\title{
What is new in the armamentarium of coronary surgeons to compete with PCI?
}

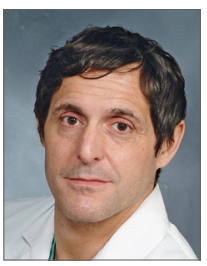

\author{
Mario Gaudino $^{1 *}, \mathrm{MD}$; David P. Taggart ${ }^{2}, \mathrm{MD}, \mathrm{PhD}$
}

1. Department of Cardiothoracic Surgery, Weill Cornell Medicine, New York City, NY, USA;2. University of Oxford, Oxford, United Kingdom

In the last two decades, the comparison between percutaneous coronary intervention (PCI) and coronary artery bypass grafting $(\mathrm{CABG})$ in the treatment of patients with multivessel and left main disease has been the object of at least a dozen large randomised controlled trials (RCTs).

One of the problems in the PCI vs. CABG debate is that, due to the continuous improvement in the technical and technological aspects of the two procedures, most of the comparative analyses are outdated soon after (or sometimes even at the moment of) their publication.

We herein describe three recent findings that will most likely result in the future in substantially superior outcomes of CABG and influence future comparisons with PCI: the greater use of guideline-directed medical therapy (GDMT), the use of additional arterial grafts (the radial artery in particular) to supplement the left internal thoracic artery to left anterior descending anastomosis, and the no-touch aortic technique.

\section{Guideline-directed medical therapy}

In a post hoc analysis of the SYNTAX trial, Iqbal and co-authors found that GDMT was underused in both groups, but especially in the surgical arm, and was closely associated with five-year outcome $^{1,2}$. The treatment effect of GDMT was even greater than the treatment effect of revascularisation strategy (26\% relative reduction in mortality with $\mathrm{CABG}$ versus PCI). Similarly, in a recent analysis of five randomised trials comparing the two revascularisation strategies, Pinho-Gomes et al showed how the compliance with GDMT is significantly lower after CABG than after PCI. Using meta-regression the authors were able to show an association between lower use of GDMT and adverse clinical outcomes in PCI versus CABG at five years, suggesting that the benefit of surgery could be markedly enhanced with more diligent secondary prevention strategies ${ }^{3}$.

\section{Additional arterial grafts}

The interim five-year analysis of the Arterial Revascularization Trial (ART - the largest trial on the comparison between the use of single vs. double internal thoracic artery grafts for CABG) reported no additional clinical benefit of a second arterial graft ${ }^{4}$. However, ART was confounded by several factors including a high rate of crossovers, frequent use of the radial artery (RA) in the single internal thoracic artery group and very high compliance 
with GDMT that may have reduced vein graft failure. The ten-year results of the trial are eagerly anticipated, by the end of this year.

Different results have been reported for the RA. After sporadic experiences in the 1970s, the RA was introduced into clinical practice as a conduit for CABG in the early $1990 \mathrm{~s}^{5}$. Since then, several RCTs and meta-analyses have shown that the patency rate of the RA is significantly better than that of the saphenous vein (SV). The difference in patency between the SV and the RA is usually not apparent in the first postoperative year, but becomes significant from four years after surgery ${ }^{6}$. In a prospective 20 -year follow-up of patients receiving RA and SV grafts, we have shown how the risk of occlusion two decades after surgery is almost threefold higher for the SV than for the RA ${ }^{7}$.

A large number of observational studies have reported that the use of the RA instead of the SV for CABG is associated with better postoperative survival. In a recent meta-analysis of 12 studies and 23,288 patients, we found that, compared to the SV, the use of the RA is associated with a $24 \%$ relative reduction in the risk of mortality at a mean follow-up of 6.7 years after surgery ${ }^{8}$. However, observational series have limitations in terms of potential for unmatched confounders and treatment allocation biases and the solidity of the conclusions based on observational data has been questioned ${ }^{9}$.

Recently, a patient-level analysis of all RCTs that compared the RA and the SV as the second conduit for CABG has shown that at five-year follow-up the use of the RA was associated with a significant reduction of major adverse cardiac events, myocardial infarction and repeat revascularisation (HR for the composite outcome $0.67,95 \% \mathrm{CI}: 0.49-0.90)^{10}$. The incidence of graft failure was also significantly lower for the RA, providing a mechanistic explanation for the clinical observations (HR for graft occlusion $0.44,95 \%$ CI: $0.28-0.70)$. This RCT-based demonstration overcame the limitations of the previous observational studies and is regarded as a definitive demonstration of the clinical benefits associated with the use of additional arterial grafts for $\mathrm{CABG}$.

To date, no RCT has compared multi-arterial CABG to PCI, and the use of additional arterial conduits in the surgical arm of the studies comparing the two techniques has generally been very limited (35\% in the SYNTAX trial). Observational data suggest that the use of additional arteries can further increase the benefit of surgery. In a single-institution propensity-matched analysis, Habib and associates found that at nine-year follow-up CABG with multiple arterial grafts, but not conventional $\mathrm{CABG}$, was associated with a statistically significant survival benefit compared to PCI with drug-eluting stents ${ }^{11}$, and Raja and associates reported similar results in another large propensity-matched series ${ }^{12}$.

The renewed interest of surgeons in the use of the RA, coupled with the increase in the use of the transradial approach for PCI and catheterisation, opens up the new question of the management of the artery in patients with coronary disease. This is of particular relevance as there is convincing evidence that catheterisation of the radial artery can lead to prolonged endothelial dysfunction and an increased risk of failure if used for $\mathrm{CABG}^{13}$. In a recent joint review on the subject some practical recommendations were made ${ }^{8}$. The most important is probably that, as most of the catheterisation laboratories are set to use the right RA and most of the surgeons prefer to use the left RA to harvest the left internal thoracic artery simultaneously, in general the cardiologists should stay to the right and the surgeons to the left. Bilateral radial procedures (either percutaneous or surgical) should be discouraged and efforts to minimise RA damage during transradial interventions (distal RA access point, miniaturised equipment, aggressive antithrombotic treatment, and patent haemostasis) actively implemented.

\section{No-touch aortic technique}

Another important evolution in CABG is the use of the an-aortic technique or no-touch aortic technique. No-touch aortic CABG implies off-pump revascularisation using only in situ internal thoracic artery and composite (Y) grafts. This technique effectively permits avoidance of any aortic manipulation and has the potential to minimise the risk of intraoperative stroke. Indeed, in the recently reported EXCEL trial where surgeons were encouraged to use intraoperative ultrasound to guide cannulation and aortic manipulation, the incidence of stroke between $\mathrm{CABG}$ and PCI, in contrast to previous RCTs, was similar. Furthermore, in a recent network meta-analysis comparing the results of $\mathrm{CABG}$ with different degrees of aortic manipulation, Zhao and associates found that the use of a no-touch aortic technique was associated with a $78 \%$ reduction in the risk of stroke compared to traditional CABG (HR 0.22, 95\% CI: 0.14-0.33) ${ }^{14}$. As intraoperative stroke has traditionally been the Achilles' heel of CABG in comparison with PCI, it is conceivable that a broader use of the no-touch technique could result in better relative results in the surgical arm.

In conclusion, technical and technological innovations on both sides continue to modify the components of the PCI vs. CABG comparison. The use of more aggressive GDMT, additional arterial grafts and the no-touch aortic technique are probably the most promising innovations on the surgical side.

Now the ball is in your court...

\section{Conflict of interest statement}

D. Taggart is Principal Investigator for the ART trial. M. Gaudino has no conflicts of interest to declare.

\section{References}

1. Iqbal J, Zhang YJ, Holmes DR, Morice MC, Mack MJ, Kappetein AP, Feldman T, Stahle E, Escaned J, Banning AP, Gunn JP, Colombo A, Steyerberg EW, Mohr FW, Serruys PW. Optimal medical therapy improves clinical outcomes in patients undergoing revascularization with percutaneous coronary intervention or coronary artery bypass grafting: insights from the Synergy Between Percutaneous Coronary Intervention with TAXUS and Cardiac Surgery (SYNTAX) trial at the 5-year follow-up. Circulation. 2015;131:1269-77. 
2. Rymer JA, Newby LK. Back to the future: improving the use of guidelines-recommended coronary disease secondary prevention at the dawn of the precision medicine era. Circulation. 2015;131: 1234-5.

3. Pinho-Gomes AC, Azevedo L, Ahn JM, Park SJ, Hamza TH, Farkouh ME, Serruys PW, Milojevic M, Kappetein AP, Stone GW, Lamy A, Fuster V, Taggart DP. Compliance With GuidelineDirected Medical Therapy in Contemporary Coronary Revascularization trials. J Am Coll Cardiol. 2018;71:591-602.

4. Taggart DP, Altman DG, Gray AM, Lees B, Gerry S, Benedetto U, Flather M; ART Investigators. Randomized Trial of Bilateral versus Single Internal-Thoracic-Artery Grafts. $N$ Engl J Med. 2016;375:2540-9.

5. Acar C, Jebara VA, Portoghese M, Beyssen B, Pagny JY, Grare P, Chachques JC, Fabiani JN, Deloche A, Guermonprez JL. Revival of the radial artery for coronary artery bypass grafting. Ann Thorac Surg. 1992;54:652-9.

6. Benedetto U, Raja SG, Albanese A, Amrani M, BiondiZoccai G, Frati G. Searching for the second best graft for coronary artery bypass surgery: a network meta-analysis of randomized controlled trials. Eur J Cardiothorac Surg. 2015;47:59-65.

7. Gaudino M, Tondi P, Benedetto U, Milazzo V, Flore R, Glieca F, Ponziani FR, Luciani N, Girardi LN, Crea F, Massetti M. Radial Artery as a Coronary Artery Bypass Conduit: 20-Year Results. J Am Coll Cardiol. 2016;68:603-10.

8. Gaudino M, Burzotta F, Bakaeen F, Bertrand O, Crea F, Di Franco A, Fremes S, Kiemeneij F, Louvard Y, Rao SV, Schwann TA, Tatoulis J, Tranbaugh RF, Trani C, Valgimigli M, Vranckx P, Taggart DP; Arterial Grafting International Consortium Alliance. The radial artery for percutaneous coronary procedures or surgery? J Am Coll Cardiol. 2018;71:1167-75.
9. Gaudino M, Di Franco A, Rahouma M, Tam DY, Iannaccone M, Deb S, D’Ascenzo F, Abouarab AA, Girardi LN, Taggart DP, Fremes SE. Unmeasured Confounders in Observational Studies Comparing Bilateral Versus Single Internal Thoracic Artery for Coronary Artery Bypass Grafting: A MetaAnalysis. J Am Heart Assoc. 2018 Jan 6;7(1).

10. Gaudino M, Benedetto U, Fremes S, Biondi-Zoccai G, Sedrakyan A, Puskas JD, Angelini GD, Buxton B, Frati G, Hare DL, Hayward P, Nasso G, Moat N, Peric M, Yoo KJ, Speziale G, Girardi LN, Taggart DP; RADIAL Investigators. Radial Artery or Saphenous Vein Grafts in Coronary Artery Bypass Surgery. N Engl J Med. 2018;378:2069-77.

11. Habib RH, Dimitrova KR, Badour SA, Yammine MB, El-Hage-Sleiman AK, Hoffman DM, Geller CM, Schwann TA, Tranbaugh RF. CABG Versus PCI: Greater Benefit in Long-Term Outcomes With Multiple Arterial Bypass Grafting. J Am Coll Cardiol. 2015;66:1417-27.

12. Raja SG, Benedetto U, Ilsley CD, Amrani M; Harefield Cardiac Outcomes Research Group. Multiple arterial grafting confers survival advantage compared to percutaneous intervention with drugeluting stents in multivessel coronary artery disease: A propensity score adjusted analysis. Int J Cardiol. 2015;189:153-8.

13. Mounsey CA, Mawhinney JA, Werner RS, Taggart DP. Does Previous Catheterization Preclude Use of the Radial Artery as a Conduit in Coronary Artery Bypass Surgery? Circulation. 2016; 134:681-8.

14. Zhao DF, Edelman JJ, Seco M, Bannon PG, Wilson MK, Byrom MJ, Thourani V, Lamy A, Taggart DP, Puskas JD, Vallely MP. Coronary Artery Bypass Grafting With and Without Manipulation of the Ascending Aorta: A Network Meta-Analysis. J Am Coll Cardiol. 2017;69:924-36. 